\title{
Can we prevent poor outcomes for children who require long intensive care stays or early reoperations?
}

\author{
John M. Karamichalis, MD, FACS
}

\footnotetext{
From The Children's Hospital at Saint Francis, Tulsa, Okla; and the University of California San Francisco, San Francisco, Calif.

Disclosures: Author has nothing to disclose with regard to commercial support.

Received for publication June 24, 2016; revisions received July 4, 2016; accepted for publication July 6, 2016 available ahead of print Aug 12, 2016.

Address for reprints: John M. Karamichalis, MD, FACS, The Children's Hospital at Saint Francis and UCSF, Pediatric Cardiac Surgery, 1414 E 39th St, Apt 404, Tulsa, OK 74105 (E-mail: john.karamichalis@ucsf.edu).

J Thorac Cardiovasc Surg 2016;152:1113-4

$0022-5223 / \$ 36.00$

Copyright (c) 2016 by The American Association for Thoracic Surgery

http://dx.doi.org/10.1016/j.jtcvs.2016.07.028
}

The article in this issue of the Journal by Namachivayam and colleagues ${ }^{1}$ retrospectively reviews the long-term survival and functional outcomes of 116 children with prolonged ( $>28$ days) stay in the intensive care unit (ICU) after cardiac surgery between 1997 and 2012. The incidence of prolonged ICU stay was significantly greater in the more recent years, which was attributed to an increased population of children with hypoplastic left heart syndrome. Their long-term outcomes were poor, with 74\% survival to ICU discharge and only $51 \%$ survival at 3 years. Among those who survived hospitalization, early reoperations, mainly for residual lesions and univentricular repair, were predictors of mortality at 3 years. The 3 -year survival among those who required early reoperations was $58 \%$, compared with $81 \%$ among those who did not ( $P=.01$ by log-rank). Among survivors, $36 \%$ had either moderate or severe disability and $13 \%$ had poor quality of life.

This is the first large-scale study reporting long-term survival and functional data of children with long stays in the ICU of children after cardiac surgery, for which Namachivayam and colleagues ${ }^{1}$ are to be congratulated. More knowledge of the various aspects of the care process of these patients and the different factors associated with results would help us to guide the care of these patients with the goal of improving outcomes. The need for early unplanned reoperation, mostly for residual lesions, negatively affected the long-term survival. One could assume that the prolonged ICU stay of these patients could be a surrogate for poor physiology related to residual lesions that necessitated corrective reoperations. Recent data on surgical technical performance scores in pediatric cardiac surgery ${ }^{2,3}$ showed that inadequate technical scores, as defined by the presence of significant residual lesions or the need for reintervention, were associated with both longer ICU stay and poor long-term survival. This is described by a "technical imperative," defined as an absolute rule whereby it is imperative to leave the operating room

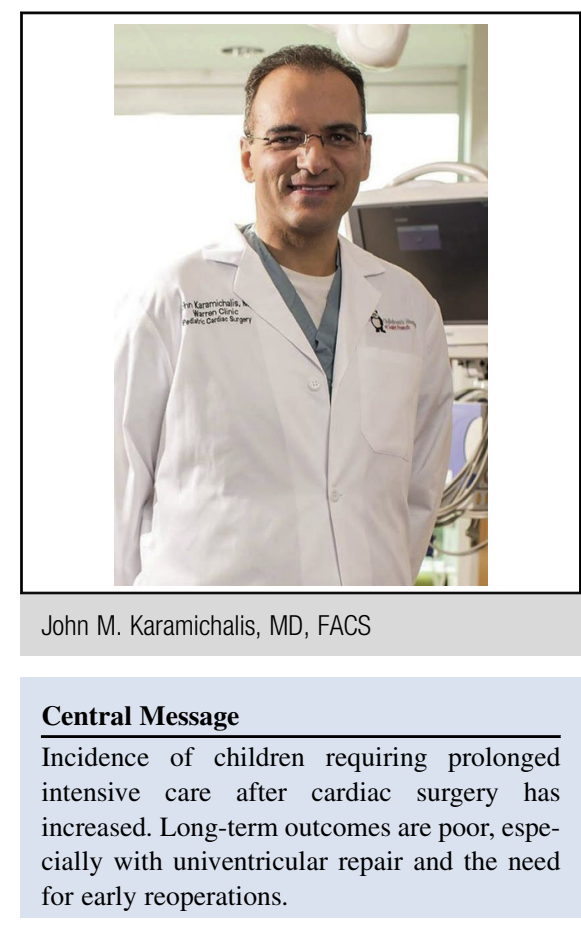

See Article page 1104.

with a good or, better yet, an optimal technical result. While this study of Namachivayam and colleagues ${ }^{1}$ did not use technical performance scores, their predictors of long-term survival, such as the need for early reoperations, are essentially surrogates for inadequate technical performance scores and could be used to categorize patients at risk for poor outcomes.

Another tool for the surveillance of postoperative patients in the ICU at high risk for poor outcomes is the Pediatric Risk of Mortality III score at admission to the ICU, which has been found to be associated with poor technical performance scores and outcomes, ${ }^{4}$ or even better the newer Pediatric Index of Cardiac Surgical Intensive Care Mortality Risk Score for Pediatric Cardiac Critical Care, which has shown better discrimination for mortality.

Further research into the causes of long ICU stay after cardiac surgery would allow us to intervene and prevent the long-term poor outcomes in this population as well as to counsel the parents appropriately regarding the longterm implications of a complicated and lengthy postoperative ICU stay. 


\section{References}

1. Namachivayam SP, d'Udekem Y, Millar J, Cheung MM, Butt W. Survival status and functional outcome of children who required prolonged intensive care after cardiac surgery. J Thorac Cardiovasc Surg. 2016;152:1104-12.e3.

2. Nathan M, Karamichalis JM, Liu H, Emani S, Baird C, Pigula FA, et al. Surgical technical performance scores are predictors for late mortality and unplanned reinterventions in infants after cardiac surgery. J Thorac Cardiovasc Surg. 2012;144: 1095-101.e7.

3. Nathan M, Karamichalis J, Liu H, Gauvreau K, Colan S, Saia M, et al. Technical Performance Scores are strongly associated with early mortality, postoperative adverse events and intensive care unit length of stay-analysis of consecutive discharges at 2 years. J Thorac Cardiovasc Surg. 2014;147: 389-96.

4. Karamichalis JM, del Nido PJ, Thiagarajan RR, Jenkins KJ, Liu H, Gauvreau K, et al. Early postoperative severity of illness predicts outcomes following stage I Norwood procedure. Ann Thorac Surg. 2011;92: 660-5.

5. Jeffries HE, Soto-Campos G, Katch A, Gall C, Rice TB, Wetzel R. Pediatric Index of Cardiac Surgical Intensive Care Mortality Risk Score for Pediatric Cardiac Critical Care. Pediatr Crit Care Med. 2015;16:846-52. 